\title{
O ESTADO DAS COISAS NO DEBATE ENTRE REDISTRIBUIÇÃO E RECONHECIMENTO
}

\author{
Luiz Gustavo da Cunha de Souza
}

Resumo: Este artigo visa dois objetivos em quatro fases: após uma breve introdução sobre a emergência de conflitos por reconhecimento, serão apresentadas as leituras e reconstruções que Nancy Fraser e Axel Honneth fazem desta situação para que, por fim, sejam apontadas direções no debate entre os modelos teóricos destes dois autores, respectivamente da redistribuição e do reconhecimento. Assim, espera-se contribuir tanto para o movimento de situar o debate entre Fraser e Honneth quanto para apontar direções para onde se dirige a teoria social contemporânea.

Palavras Chave: Redistribuição; reconhecimento; teoria social contemporânea; Axel Honneth; Nancy Fraser.

Abstract: This article tries to present a brief reconstruction of the debate between Nancy Fraser and her theory of redistribution and Axel Honneth and his theory of recognition. Four steps shall be taken, the first of which is an introduction for the theme of the struggles for recognition. After this, understandings of both Fraser and Honneth about this situation must be separately taken, so that, as a conclusion for the article, the directions for the reconstruction of a Critical Social Theory coul emerge form this confrontation of their models. Thus it could be that the work of situating the debate itself runs together with the attempt to set direction for the research on the question of redistribution and recognition.

Keywords: Redistribution; recognition; contemporary social theory, Axel Honneth; Nancy Fraser.

${ }^{1}$ Doutorando do Programa de Pós-graduação em Sociologia da UNICAMP. 
| 184 |

O estado das coisas no debate entre...

\section{Introdução}

O debate entre redistribuição e reconhecimento nas ciências sociais não começa com a publicação do livro conjunto de Nancy Fraser e Axel Honneth (Fraser and Honneth, 2003) e nem com as primeiras publicações destes autores, mas é parte de um giro em direção à análise de mudanças políticas e sociais ocorridas já no final da década de 1960 (Isin and Wood, 1999, Seidman and Alexander, 2001). Como afirmam Engin F. Isin e Patricia K. Wood, neste período surgem lutas sociais que não colocavam a conquista da redistribuição e da igualdade materiais entre seus princípios e, por isso, aparecem como um questionamento diferente aos fundamentos do capitalismo e da democracia, pois afirmavam que sob os discursos da cidadania universal e igualdade perante a lei subsistiam formas sistêmicas de marginalização e desrespeito. Estes movimentos representavam demandas descentralizadas frente ao sindicalismo clássico e abriram espaço para grupos identitários tais quais as feministas, os homossexuais ou os ambientalistas, entre outros, como atores sociais. Isso leva ao que Steven Seidman e Jeffrey C. Alexander chamam de um movimento da teoria social em direção a um pós-fundacionalismo, onde as teorias sociais baseadas em pressupostos centralizados, como é o caso da igualdade econômica, são colocadas em questão. Se, por um lado, o surgimento de movimentos contestatórios de um novo tipo demandava novas explicações, por outro lado, porém, estas explicações deveriam procurar oferecer novos paradigmas normativos baseados nestas formas de contestação.

Neste contexto, então, as teorias sobre as políticas da diferença e o multiculturalismo começam a aparecer, tendo em Charles Taylor, já na década de 1990, seu primeiro grande expoente. Sua preocupação principal é a análise e explicação das mudanças por que passava o quadro institucional das sociedades modernas, as demandas feitas por movimentos contestatórios a este quadro e, consequentemente, os novos problemas colocados às ciências sociais ${ }^{2}$. Entre estes, alguns

\footnotetext{
${ }^{2}$ A este respeito os livros editados por Willett, Theorizing multiculturalism, e por Seidman e Alexander The new social theory reader são instrutivos sobre
} 
pretenderam aproximar-se do modelo crítico de Jürgen Habermas, o que os coloca em diálogo também com a idéia de uma teoria crítica da sociedade capitalista, onde as questões das lutas sociais colocam em pauta não apenas novos modelos institucionais dentro da sociedade capitalista, mas também a possibilidade de sua superação. Esta orientação para a emancipação na análise destas lutas é o que caracteriza, por exemplo, os trabalhos de Fraser e Honneth, que explicitamente disputam esta herança crítica, mas não é exclusividade destes autores.

Esta orientação para a emancipação pode ser observada no trabalho de Iris Marion Young, Justice and the politics of difference, de 1990, que defende que, em função das demandas dos novos movimentos, é o próprio paradigma de justiça que deve ser repensado. Assim, como afirma Cynthia Willett, a teorização do capitalismo contemporâneo, uma vez aceita a marca do multiculturalismo, deve tomar a multiplicidade de perspectivas oferecidas por estes movimentos de contestação como um contraponto à narrativa singular clássica que caracterizou a filosofia moderna (Willett, 1998), que é aquela que aponta para a igualdade material como o paradigma de justiça. À crítica de Habermas ao paradigma do trabalho (Habermas, 1968, 1984) é, então, adicionada a proposição de que o paradigma comunicativo seja também o da integração social da diferença ao invés da igualdade homogeneizada. Neste movimento, o modelo de Young para um paradigma renovado de justiça que inclua demandas que ultrapassem as condições materiais de bem estar e adentrem o campo do respeito pela diferença aparece como uma forma de caracterizar as sociedades modernas como uma ordem social em que a injustiça opera tanto ao nível da desigualdade material quanto ao nível da desigualdade simbólica. Em seus escritos,

a abrangência do debate levantado por estes novos movimentos reivindicativos, pois se tratam, nos dois casos, de coletâneas que pretendem oferecer visões de diferentes áreas da pesquisa social sobre o o problema do multiculturalismo (caso do livro de Willett) ou sobre aso problema do 
| 186 |

O estado das coisas no debate entre...

porém, a questão ainda é atrelada à discussão sobre as políticas de resguardo e respeito à diferença, isto é, as lutas sociais daqueles movimentos surgidos na década de 1960 são tratadas por ela como reivindicações por direitos políticos e sociais.

Contudo, com a entrada de Nancy Fraser e Axel Honneth no debate sobre as formas de contestação no capitalismo tardio, a questão originalmente proposta por Young sobre a revisão do paradigma de justiça é aprofundada e colocada ao lado da questão sobre a possível concorrência entre as lutas por reconhecimento e redistribuição. Isto porque Fraser e Honneth compartilham de um diagnóstico de tempo que remete, novamente, ao modelo habermasiano do esgotamento do paradigma do trabalho (Fraser and Honneth, 2003), mas buscam soluções diferentes para a sua atualização, que culminam no debate realizado por eles sobre a melhor alternativa para uma análise ad sociedade contemporânea na tradição da Teoria Crítica da sociedade, se através de um paradigma da participação política igualitária ou de um paradigma unificado de reconhecimento.

As questões sobre a revisão do paradigma de justiça e sobre a possível concorrência entre redistribuição e reconhecimento, então, poderiam ser enquadradas como faces do debate sobre o potencial normativo da idéia de reconhecimento e sua relação com as lutas tradicionais por redistribuição ${ }^{3}$. Desta forma, em um primeiro momento, como colocado por Barbara Hobson (Hobson, 2003), não se trata tanto de apontar para a concorrência entre estas duas formas de reivindicações quanto de procurar as

multiculturalismo (caso do livro de Willett) ou sobre as mudanças vividas pela teoria social desde o final dos anos 1960 (caso do livro de Seidman e Alexander).

${ }^{3}$ Poderiam também ser caracterizadas como etapas da discussão, por meio de uma hierarquização segundo a qual primeiro - inclusive por sua precedência histórica - seriam situadas as intervenções que dizem respeito à disputa entre políticas de reconhecimento versus políticas de redistribuição, seguida pela situação das questões relativas à construção filosóficas do paradigma do reconhecimento e, finalmente, do embate normativo entre os conceitos de redistribuição e reconhecimento. Por mais, 
formas como ambas se interrelacionam, dado que a grande novidade representada pelos movimentos sociais que lutam por reconhecimento leva à necessidade de reformular as ferramentas analíticas para entendê-los; assim, a necessidade de esclarecimento sobre os conceitos de redistribuição e reconhecimento, seu potencial normativo e sua limitações fica explícita e apenas como um passo final a comparação entre os dois paradigmas como alternativas para a reconstrução de uma Teoria Crítica da sociedade e para a representação da justiça poderia ser analisada, ou seja, não se trata de tomar as lutas por reconhecimento como antípodas às lutas clássicas por justiça distributiva, mas de analisar a validade dos conceitos normativos de redistribuição e reconhecimento em suas versões apersentadas por Fraser e Honneth. Este trabalho deve levar em conta, pois, que outros autores que contribuem para o tema não necessariamente participam deste debate que foi aqui caracterizado em sua forma ampla. Pelo contrário, esta participação pode ser feita exatamente da forma oposta por meio da intervenção em apenas uma das faces, pela colocação de novas questões ou mesmo pelo debate com apenas um dos participantes e suas idéias. Por isso, esta caracterização do estado do debate entre redistribuição e reconhecimento deve ser entendida como um empreendimento organizativo, já que não visa esgotar as questões levantadas em suas diferentes faces. Além disso, por meio deste mapeamento das questões levantadas nos diálogos e críticas que se seguem pretende-se identificar os temas centrais do debate, e, ao mesmo tempo, ajudar na estruturação e sistematização daquela questão inicial sobre o potencial crítico normativo dos paradigmas de redistribuição e reconhecimento.

porém, que esta hierarquização temporal não pareça errada, o fato de que não é possível realizá-la para os dois primeiros tópicos (políticas de reconhecimento versus políticas de redistribuição e o que, afinal, é reconhecimento?) parece sugerir que tratá-las como faces do debate talvez seja mais apropriado. 
| 188 |

O estado das coisas no debate entre...

Este texto pretende, então, realizar uma exposição crítica dos conceitos de redistribuição (I) e reconhecimento (II), seguida por um apontamento sobre qual é o estado atual do debate (III) e concluir com um comentário sobre as potencialidades que parecem mais promissoras após este percurso (IV). Como já dito, não se trata de esgotar o tema, mas de situá-lo no âmbito da teoria social contemporânea. Com isso, espera-se também oferecer um esclarecimento sobre a importância do debate entre Fraser e Honneth tanto para a análise do capitalismo tardio quanto para a reconstrução da Teoria Crítica.

\section{I: O paradigma material da redistribuição}

No que diz respeito àquilo que foi caracterizado como a primeira das faces do debate, a emergência de novos movimentos e demandas como formas de contestação e sua possível tendência à substituição dos movimentos voltados à distribuição material, a participação de Fraser em debates foi claramente maior do que a de Honneth, inclusive por meio de diálogos, por exemplo, com Iris M. Young, Judith Butler e Anne Phillips ${ }^{4}$. Nestes, a questão central pode ser identificada como se referindo a um argumento levantado por Fraser em um texto de 1995, "From redistribution to recognition? Dilemmas of Justice in a "Post-socialist" age"(Fraser, 2001). Ali, a autora expressa seu temor de que as demandas por reconhecimento venham a substituir as demandas por justiça material que, em sua visão, ainda estão no centro do debate sobre a justiça social, lembrando inclusive que a emergência destes movimentos deu-se em uma infeliz coincidência com o recrudescimento dos governos de direita no continente europeu e os ataques que desmantelaram o Estado social naquele continente. Em resposta, Young (Young, 1998) defende a visão de que estes movimentos por reconhecimento também estão preocupados com as demandas materiais passíveis de ser

\footnotetext{
${ }^{4}$ Ver Fraser 2008.
} 
alcançadas, sendo a própria separação entre lutas de cunho material e lutas de cunho cultural uma forma de reducionismo que poderia ser evitada por meio daquilo que ela chama de pluralização das categorias, impedindo assim que as lutas fossem vistas como fins em si mesmos e prisioneiras de categorias estáticas - por mais, vale dizer, que Fraser, a autora da separação entre lutas materiais e lutas culturais, frise que esta é uma distinção puramente analítica. Por isso, diz Young, ao invés de separar rigidamente questões de economia e cultura seria mais apropriado

\begin{abstract}
conceitualizar questões de justiça envolvendo reconhecimento e identidade como possuindo inevitáveis fontes e consequências materiais sem, com isso, serem redutíveis a dinâmicas de mercado ou exploração e privação econômicas ${ }^{5}$
\end{abstract}

Esta perspectiva é chamada por Young de "materialismo cultural" (Young, 1998) e pretende superar, resguardando o valor das lutas por reconhecimento e suas políticas, a distinção entre políticas de reconhecimento e políticas de redistribuição. Fraser, no entanto, argumenta que, com sua distinção entre políticas de redistribuição e políticas de reconhecimento, ela procurara justamente mostrar que é possível haver políticas dos dois tipos e que a separação entre ambas é uma falsa antítese afirmada exatamente na política pós-socialista, em que o valor normativo da idéia de redistribuição - entendida em seu sentido mais amplo, relacionado à justiça - perde sua força. Desta maneira, ela pretende responder a Young afirmando que seu esforço visa, antes,

\footnotetext{
${ }^{5}$ Young, 1998, p. 58, traduzido de: "to conceptualize issues of justice involving recognition and identity as having inevitably material economic sources and consequences, without thereby being reducible to market dynamics or economic exploitation and deprivation".
} 
| 190 |

O estado das coisas no debate entre...

rearticular os paradigmas de reconhecimento e redistribuição em uma noção ampla de justiça participativa. No lugar de uma separação entre movimentos culturais e movimentos redistributivos, portanto, ficaria um dualismo perspectivista que iluminaria as dimensões que compõem a luta social (Fraser, 1998) e seria posteriormente desenvolvido sob a forma do princípio unificado de paridade de participação (Fraser, 2003a, 2003b). Ou seja, Fraser deseja tomar a distinção analítica entre redistribuição e reconhecimento como ponto de partida para a formulação de um conceito de justiça em que ambos sejam reintegrados sob a forma de dimensões políticas.

Mesmo que analítica, contudo, sua distinção é motivo de crítica: para Christopher Zurn (Zurn, 2003), sem um modelo que leve em conta o reconhecimento como uma fonte específica de injustiça, perde-se o ponto de originalidade das reivindicações destes movimentos, que é o sentimento de sofrimento moral em oposição ou ao lado do sentimento de desigualdade social, isto é, o sentimento de que a socialização do indivíduo em um determinado grupo não é vista como bem vinda, ainda que ele seja parte deste grupo. Zurn, então, entende que a tentativa de Fraser de preservar a dimensão material das demandas sociais deixa de lado a noção de que sentimentos de sofrimento de injustiça não são separados de sentimentos morais. O modelo dualperspectivista, então, não seria, seguindo as indicações de Zurn, capaz de incluir em seu núcleo analítico o ponto específico de diferenciação entre os paradigmas de justiça do trabalho e dos movimentos identitários. Apesar de diagnosticar uma era "póssocialista", e, por isso, construir um paradigma amplo de justiça que inclui as dimensões da redistribuição e do reconhecimento, Fraser não abandona completamente, em seu dualismo perspectivista, aquele primeiro paradigma. Esta situação fica clara em sua afirmação de que o que deve ser reconhecido não é a diferença dos participantes, mas seu status universal de seres humanos (Fraser, 2007). Neste modelo refinado, ela mantém o dualismo perspectivista como o método teórico, mas propõe que a paridade de participação em espaços públicos de tomada de 
decisões signifique a garantia de respeito tanto material, com condições dignas de participação, quanto simbólico, com garantias de respeito à pessoa individual. Segundo Lawrence Blum (Blum, 1998), esta manutenção, por parte de Fraser, da preocupação com o aspecto político e econômico das desigualdades, que não poderia ser reduzido a uma teoria da diferença, é positivo, mas ela também corre o risco de deixar de lado a realização de idéia de reconhecimento em favor de um conceito vago de igualdade de participação - que é, enfim, a leitura de Blum sobre a proposta de paridade participativa com reconhecimento do status. Ambas as críticas revelam, pois, que o modelo de Fraser revela-se insatisfatório como resposta às questões colocadas pelas lutas por reconhecimento, entendidas como afirmações da necessidade de integrar socialmente diferentes grupos, a despeito desta construção teórica manter como pontos positivos, por um lado, atenção às demandas materiais e, por outro, um sólido ancoramento empírico nas experiências de mobilizações tornadas públicas e na sua forma de superação por meio das garantias de participação igualitária.

Estas limitações, no entanto, ganham especial relevância em vista da afirmação de Engin e Wood de que entender os direitos de cidadania em termos de direito a uma identidade ao invés de direito ao status de cidadão altera tanto o conceito de cidadania quanto a concepção corrente sobre os meios de obtê-la e suas formas (Engin e Wood, 1999). Nesta mesma linha, Hobson (Hobson, 2003) entende que as formas de contestação que demandam reconhecimento partem do ponto implícito de que, além de infligir sofrimento, as formas de desrespeito e subreconhecimento são também formas de opressão social e demandam tratamento tão sério quanto todas as formas de desvalorização do sujeito. Para isso o foco analítico deve ser alterado dos direitos propriamente ditos para as demandas por direitos, do quadro institucional para a sua crítica (Engin e Wood, 1999). 
| 192 |

O estado das coisas no debate entre...

Hobson, aliás, faz uma importante ressalva na introdução do livro Recognition struggles and social movements ${ }^{6}$ : enquanto os teóricos dos movimentos sociais têm por preocupação primordial a ação social e sua implicações na política institucional, a teorização das lutas por reconhecimento é, antes de mais nada, uma teorização com aspectos normativos (Hobson, 2003). Isso significa que, em sua visão, enquanto os movimentos sociais teriam por objetivo estabelecer relações com o quadro político de uma sociedade, os movimentos por reconhecimento visariam alterar este quadro. No caso da teoria social de Fraser, então, não seria exagerado falar de um déficit normativo em favor de um maior aprofundamento da análise dos movimentos contestatórios.

\section{II: O paradigma moral do reconhecimento}

Quanto às teorias que lidam com o reconhecimento, entretanto, Hobson apresenta outra ressalva: mesmo tendo notado que a formação da identidade é um ponto central para as lutas sociais, estes teóricos não conseguem apontar com a necessária clareza para a importância do contexto institucional na formação dos movimentos contestatórios (Hobson, 2003). Se, então, os teóricos que fundamentam seus modelos em aspectos mais empíricos perdem de vista a importância normativa do processo de formação da personalidade e os teóricos do reconhecimento acabam preocupando-se mais com a alateração do quadro institucional da sociedade do que com o surgimento dos movimentos, Honneth pretende contribuir para o debate a

\footnotetext{
${ }^{6}$ Este trabalho, a propósito, reúne diferentes artigos sobre pesquisas empíricas que são resultado de um grupo de pesquisas conduzido por Barbara Hobson e que oferece um panorama das políticas, demandas e lutas por reconhecimento em diferentes lugares e com relação a diferentes temas, precedidas por um artigo teórico de Fraser e seguidas por um epílogo de Anne Phillips. Infelizmente, também aqui a questão de um aprofundamento normativo sobre o conceito de reconhecimento não é realizada a contento.
} 
partir de uma proposta em que a análise "gramática moral dos conflitos sociais" forneça elementos de superação tanto do déficit normativo quanto do déficit sociológico destes modelos e, ao memso tempo, supere as limitações que ele identifica nos modelos de Teoria Crítica anteriores.

Segundo Hobson, as lutas por reconhecimento não diriam respeito somente a um processo de relação consigo mesmo em que o não atendimento das expectativas normativas do sujeito o levaria ao sofrimento e à luta para alterar esta situação, conforme ela entende a explicação de Honneth. Para ela, o movimento que ele vê como posterior, a articulação do sofrimento ao nível social, já faz parte da luta por reconhecimento de maneira indivisível, sendo o momento de sua articulação contestatória das normas institucionalizadas ${ }^{7}$. Em outras palavras, com esta crítica Hobson afirma que aquilo que Honneth vê como um processo formativo ela entende que seja uma expressão de contestação a padrões de denegação e sub-valorização da identidade de um sujeito. Esta visão, que pretende desenfatizar a idéia de reconhecimento como padrão normativo de justiça, é compartilhada por Anne Phillips (Phillips, 2003), para quem a necessidade do reconhecimento e sua importância como uma esfera na qual o indivíduo deve sentir que recebe tratamento justo e igualitário é um imperativo, ao passo que as lutas por reconhecimento dizem respeito antes à capacidade dos grupos que as realizam de serem ouvidos do que à dignidade e atenção às suas particularidades (Phillips, 2003). Estes comentários de Hobson e Phillips, que procuram valorizar as lutas por reconhecimento frente ao modelo de Fraser, ainda

\footnotetext{
${ }^{7}$ A este respeito vale a nota de que, no entendimento de Honneth, o processo de articulação social da busca do reconhecimento em uma luta coletiva é diferente da idéia pura de reconhecimento mas é também um processo necessariamente presente na formação bem sucedida dos sujeitos que passaram por experiências de desrespeito, isto é, a luta precisa estar junto com o reconhecimento, pois do contrário este poderia ser um modelo ahistórico em que seu conteúdo de reconhecimento é previamente dado. Ver Souza, 2009.
} 
| 194 |

O estado das coisas no debate entre...

não apontam, porém, com firmeza para parâmetros normativos que vão além de uma democracia participativa que respeite os direitos grupais, algo que a própria Fraser já fizera. Neste sentido não respondem à questão de Young sobre como se constituiria um paradigma de justiça preocupado com a inclusão das lutas por reconhecimento; também não avançam para além da distinção analítica de Fraser e sua preocupação com a forma de resolver e integrar as demandas por redistribuição e reconhecimento; e, por fim, indicam um possível caminho de crítica a Honneth e sua tentativa de construir um novo paradigma de justiça baseado no reconhecimento e não na democracia ${ }^{8}$, mas também não vão além da indicação.

Neste sentido, a construção de um paradigma em que a justiça remeta tanto às esferas de vida social quanto à integridade da personalidade é o que Honneth (Honneth 2003a, 2007) tenta fazer. Esta tentativa, porém, não abre mão de uma herança crítica quanto às questões imanência e transcendência, referente à primeira geração de teóricos críticos, cujo autor central é Max Horkheimer e seus trabalhos da década de 1930; ao mesmo tempo, Honneth não abandona o movimento de refundação da Teoria Crítica realizado por Habermas, em que o espaço moral pré-teórico de ação, que é onde se encontraria o espaço da crítica, deve ser buscado no processo intersubjetivo de socialização. Assim, sua pretensão, segundo Zurn (Zurn, 2005) é

\footnotetext{
${ }^{8} \mathrm{Na}$ terceira parte de seu Luta por reconhecimento (2003), Honneth propõe a idéia de uma revisão dos parâmetros de avaliação histórica. Em vista dos modelos aqui defendidos por Phillips e também por Maclure (2003) fica mais nítida a importância daquele movimento para sua tese: enquanto no caso destas autoras - e também de Fraser e muitos outros - a questão ainda é encontrar uma forma de melhor e mais justo funcionamento da democracia, no modelo de Honneth o funcionamento democrático não é a finalidade explícita, mas sim uma sociedade baseada na eticidade e no respeito pela diferença - cujo procedimento parece ser, de qualquer forma, um modelo democrático-comunicativo inspirado em Habermas.
} 
renovar a crítica aos padrões distributivos do capitalismo por meio de um ponto de partida normativo implícito em experiências cotidianas: reações a violações de relações apropriadas de reconhecimento intersubjetivo ${ }^{9}$

Em consonância com esta definição de Zurn, Jean-Philippe Deranty (Deranty, 2005) afirma que a idéia mesma de uma "ética do reconhecimento" representa um potencial, frequentemente subvalorizado, de crítica política e social porque está atenta ao fato de que a reprodução da vida social se dá por meio de parâmetros normativos que permitem a realização bem sucedida da vida dos membros de uma sociedade e que estes membros podem relacionar-se com estes parâmetros também de modo negativo, a partir de privações e desrespeito.

O modelo da teoria do reconhecimento de Honneth, então, busca na "gramática social dos conflitos sociais" este potencial observado por Deranty, localizando ali expectativas de reconhecimento e padrões de desrespeito intersubjetivos que remetem a normas de sociabilidade - ou à ignorância destas normas (Honneth, 2003a). A teoria do reconhecimento lida, pois, com dois pontos de apoio para a construção de um modelo ao mesmo tempo imanente e transcendente: por um lado Honneth procura no processo de formação individual a construção de expectativas normativas sobre a personalidade dos sujeitos e por outro ele vê nas práticas de desrespeito a estas expectativas o combustível à crítica das formas de socialização existentes ${ }^{10}$. Ou seja, o momento de imanência de sua teoria se encontra nas

${ }^{9}$ Zurn, 2005, traduzido de "[the strategy is thus to] renew the critique of the distributive patterns of capitalism by means of a normative standpoint implicit in everyday experiences: reactions to violations of appropriate relations of intersubjective recognition." (p. 90)

${ }^{10}$ Isto implica em uma diferença fundamental enrte seu modelo teórico e o de Fraser: enquanto a norte-americana vê a sociedade capitalista como uma ordem de status com diferentes esferas, Honneth a entende como uma rede de relações intersubjetivas de reconhecimento. 
| 196 |

O estado das coisas no debate entre...

práticas correntes de negação de reconhecimento, enquanto sua realização potencial representa o momento transcendente. Desta maneira, como ele argumenta em seu debate com Fraser (Honneth, 2003b), é possível a construção de uma estrutura analítica unificada, que ele chama de um "monismo normativo" (Honneth, 2003b e 2003c). Este monismo normativo seria uma alternativa à separação entre demandas materiais, culturais e de qualquer outro tipo. Para Honneth, um paradigma crítico baseado no processo de formação bem-sucedida da personalidade leva em conta os momentos de formação da autonomia individual, reconhecimento de valor universal da personalidade e estima pelas suas capacidades particulares, o quê, traduzido em termos de integração social significa que ele acredita que o modelo do reconhecimento não se limita à dimensão moral das lutas sociais, mas pretende oferecer, graças a este seu monismo, uma resposta unificada às dimensões de injustiça (Honneth, 2003a). Isso significa dizer que a separação analítica entre as lutas de acordo com suas demandas primordiais, como feita por Fraser, nem mesmo existe. No modelo do reconhecimento teorizado por Honneth mesmo a dimensão material da injustiça é constituída como uma forma de desrespeito.

Uma vez, portanto, que Honneth pretende teorizar o reconhecimento como um paradigma para o processo de formação bem sucedida da identidadee daí derivar um entendimento mais amplo sobre a idéia de justiça, os debates com sua proposta devem se preocupar com um tipo diferente de questão: a fundamentação de um conceito de reconhecimento que possa ocupar de modo consequente o espaço analítico destinado à crítica em uma teoria social. Se para a face anterior do debate, na qual Fraser se destacou, o tema central era a preocupação com os efeitos e consequências das lutas por reconhecimento, neste momento de debate, então, o que está em jogo é a validade ou não do conceito de reconhecimento como um paradigma crítico. Para isso devem ser levadas em conta suas duas dimensões, conforme teorizadas por Honneth: de um lado seu potencial crítico e do outro sua relação com a formação dos sujeitos e das lutas sociais. 
Pensando sobre o potencial crítico deste modelo, Dieter Freundlieb (Freundlieb, 2000) observa na teoria do reconhecimento de Honneth não mais que uma extensão e um desenvolvimento daquilo que já está implícito no modelo de Habermas, que é o reconhecimento de parceiros autônomos e de sujeitos moralmente responsáveis como o fundamento da vida social. Para Freundlieb, a necessidade de reconhecimento identificada por Honneth é somente uma nova roupagem à noção habermasiana de transcendência intramundana. Além disso, ele questiona neste modelo a caracterização mesma da subjetividade como intersubjetivamente constituída. Diz ele que a recusa de Habermas e Honneth em adotar uma teoria da subjetividade em lugar da teoria da intersubjetividade atrapalharia o próprio intento de reconstruir a Teoria Crítica, pois uma fundamentação reflexiva da subjetividade poderia oferecer uma base mais sólida para aquela transcendência intramundana (Freundlieb, 2000). Neste caso, é o retorno à filosofia do sujeito no lugar da antropologia intersubjetiva do reconhecimento que é sugerido como uma alternativa para a reformulação normativa pretendida por Honneth: Freundlieb acredita que o reconhecimento não é capaz de fundamentar uma crítica da sociedade presente porque o projeto de transcendência não poderia ser solidamente ancorado em relações interpessoais, mas precisaria ser fundado em um movimento de reflexão, no qual o retorno ao sujeito de um sentimento de integridade, e não o sentimento de integridade no outro, é que funcionaria como parâmetro para a crítica imanente e para a proposição da transcendência. Esta visão, entretanto, vai de encontro à interpretação de Carl-Goran Heidegren (Heidegren, 2002), para quem a teoria do reconhecimento seria construída a partir de uma antropologia derivada da tipologia hegeliana do reconhecimento - constituída por amor, direitos e estima social. Isto significaria que uma teoria do reconhecimento como a de Honneth, menos que preocupar-se com questões multiculturais procuraria, por meio desta construção intersubjetiva, oferecer uma base crítica para a transcendência intramundana, exatamente ao contrário do que sugere 
| 198 |

O estado das coisas no debate entre...

Freundlieb ${ }^{11}$. Segundo Heidegren, ao fundar o momento de transcendência nesta versão intersubjetiva da antropologia, Honneth não se preocupa primordialmente com a integração social da diferença e sim com a formulação de uma norma de sucesso para o desenvolvimento de sujeitos autônomos para a vida social.

Esta última afirmação, contudo, indica que Honneth, mesmo com a construção de um modelo normativo amplo o bastante para enfrentar de forma eficiente o princípio democrático participativo de Fraser, parece caminhar em direção contrária à teoria social: ao contrário do que ele se propusera ao lançar as bases de sua teoria, o momento de imanência de seu modelo aponta antes para a não realização do horizonte normativo de seu modelo do que para a gramática dos conflitos sociais, ou seja, a ênfase no momento da psicologia formativa da teoria do reconhecimento coloca é realizada ao custo da atenção ao nexo sociológico entre o desrespeito a este processo de formação e as lutas sociais. Assim, a gramática moral dos conflitos sociais parece atentar para as relações morais mas não para os conflitos sociais.

\section{III: O estado das coisas}

O apontamento de críticas externas às concepções teóricas de Fraser e Honneth ajuda, então, a iluminar pontos importantes para a confrontação crítica destes dois paradigmas de reconstrução da idéia normativa de justiça, ou seja, da confrontação entre o modelo de Fraser e sua tentativa de incluir as demandas por reconhecimento em um paradigma clássico de justiça tornado

\footnotetext{
${ }^{11}$ Ranke (Ranke, 2005), porém, questiona qual o sentido que Honneth dá ao termo integridade pessoal e qual a sua relação com a tipologia do reconhecimento que Heidegren vê como a base antropológica deste modelo, já que a formação íntegra de uma identidade posteriormente precisaria ser tratada como uma demanda válida ou não dos movimentos que lutam por reconhecimento, remetendo novamente o modelo honnethiano ao debate com o multiculturalismo.
} 
mais robusto e o modelo de Honneth que entende que a idéia mesma de justiça deve ser objeto de um esclarecimento conceitual que revele seu caráter moral. Ainda que ambos os autores reivindiquem oferecer soluções para ambos os tipos de desigualdade, também se prontificam a notar ausências no modelo concorrente. Não é novidade, portanto, procurar os pontos de interconexão e diálogo entre eles, trabalho, aliás, já realizado não apenas por Fraser e Honneth, mas também por vários dos autores citados neste texto e por alguns dos responsáveis por sua recepção no Brasil (Silva, 2002, 2005, 2008 e 2009, Neves, 2005, Mattos, 2006, Mendonça, 2007, Pinto, 2008). Porém, como fica claro após esta revisão do estado das coisas no debate entre redistribuição e reconhecimento, poucos trabalhos se preocupam com o esclarecimento sobre cada um dos modelos e sua interrelação. Lembrando que aqui não se buscava o esgotamento do tema, mas um mapeamento das direções do debate fica claro que ao invés do trabalho de buscar pontos que conectem políticas de redistribuição e reconhecimento ou questionem qual o melhor diagnóstico para o entendimento e crítica do capitalismo contemporâneo, faz-se necessário realizar um estudo profundo sobre estes modelos a fim de entender, por meio de suas relações entre si e com a Teoria Crítica, as potencialidades teóricas de cada um deles como formas de teorização da justiça social ${ }^{12}$.

$\mathrm{Na}$ medida em que os debates levantados por autores como Young, Hobson, Phillips, Zurn e Freundlieb, entre outros,

\footnotetext{
${ }^{12}$ A respeito da bibliografia usada neste texto, deve ser notado que o debate entre Fraser e Honneth é um sustentáculo para muitas e as mais diversas discussões, como exemplifica o livro organizado por Barbara Hobson sobre as lutas por reconhecimento e os movimentos sociais. Também a participação de cada vez mais autores nos debates sobre este tema, seja em apenas uma de suas faces, seja nele como um todo pode ser exemplificado tanto pela entrada de um autor consagrado como Paul Ricouer ou mesmo a atenção devotada por Habermas ao tema, quanto pela abrangência de publicações dedicadas a Fraser ou Honneth nos últimos.
} 
$|200|$

O estado das coisas no debate entre...

indicam que este estado de coisas no debate entre redistribuição e reconhecimento ainda é o da busca por um modelo normativo capaz de responder às necessidades desta teorização ampla da justiça social, talvez não seja descabido afirmar que a questão para onde apontam os trabalhos de Fraser e Honneth é a de como integrar processos de formação intersubjetiva de nível psíquico com processos de socialização em uma estrutura democrática. Se a teoria do reconhecimento de Honneth ainda parece mais apta a realizar a primeira tarefa, ela ainda deve muito no que diz respeito à caracterização dos conflitos sociais. Ainda que notável, a importância dada por Honneth aos processos de formação psíquica ainda não é suficiente para a construção de uma teoria social onde as lutas por reconhecimento estabeleçam novos parâmetros normativos de socialização. Neste respeito, a explicitação discursiva das demandas, como proposta por Fraser, parece um momento necessário das lutas.

Assim, por meio de uma leitura que coloque os modelos de Fraser e Honneth à prova não apenas a partir de suas próprias construções ${ }^{13}$, mas também por meio de uma confrontação crítica, seria possível procurar tanto no diagnóstico de tempo destes autores quanto em suas construções normativas os elementos desta Teoria Crítica reconstruída, como parecem ser a necessidade de integração social da diferença observada por Fraser e a formulação de um conceito amplo de justiça que dê conta das dimensões psíquicas e materiais ao mesmo tempo como esferas de desrespeito às expectativas dos sujeitos, como vê Honneth. Lembrando que tanto Young quanto Zurn atentam para a face reconstrutiva da teoria social crítica que é analisar a emergência destes novos conflitos, a importância de um debate como o de Fraser e Honneth pouco pode ser subvalorizada. Como fica claro nos debates decorrentes das obras destes dois autores, esferas como a importância da subjetividade, tratada por Freundlieb e Zurn, o potencial moral das lutas, lembrado por Deranty, a necessidade

\footnotetext{
${ }^{13}$ A respeito do procedimento da crítica imanente, ver Kauppinen, 2002.
} 
de formalização de um conceito rigoroso de inclusão da diferença, porposto por Blum, e também a importância da relação entre os valores expressos por esta integração da diferença e o quadro instittucional do capitalismo tardio, da qual falam Phillips e Hobson, todos estes são elementos que adentram a arena da teoria social como desdobramentos ou consequências deste movimento de retorno à teorização ampla pretendido por Fraser e Honneth (Fraser and Honneth, 2003).

Por fim, em função da confrontação crítica entre os modelos de paridade participativa e da teoria do reconhecimento, aparecem ainda contribuições ao debate focadas em problemas mais específicos, seja na esfera política, com o uso destes conceitos como representações formas de sociabilidade contra-hegemônicas, realizada por Boaventura de Sousa Santos (Santos, 2001), ou na esfera sociológica, onde Josué Pereira da Silva (Silva, 2008 e 2009) pretende buscar na discussão da redistribuição e reconhecimento alternativas para uma fundamentação universalista das políticas públicas.

\section{IV - Conclusão}

As críticas de Fraser à adesão da teoria social às lutas por reconhecimento e às tentativas de reduzir redistribuição e reconhecimento a um mesmo conceito indicam que ela não está convencida de que demandas culturais poderiam ser uma boa alternativa para basear a crítica do capitalismo contemporâneo, o que equivale a dizer que ela ainda aposta no paradigma distributivista como um padrão normativo mais apto a enfrentar as demandas de uma era pós-socialista por ser mais atento às questões de igualdade material, ou seja, mesmo frente ao monismo normativo de Honneth, Fraser mantém a necessidade de uma distinção analítica que resulte em um principio unificado capaz de remediar as diferentes dimensões da injustiça (Fraser, 2003a e 2003b), ainda que isto pareça contradizer seu próprio diagnóstico de uma era pós-socialista. Por outro lado, Zurn (Zurn, 2005) afirma que Honneth apenas recentemente parece ter se 
|202 |

O estado das coisas no debate entre...

preocupado mais seriamente com a relação entre estas e as demandas não materiais - ou, colocando nos termos honnethianos, com a dimensão das demandas materiais no modelo da teoria do reconhecimento, buscando um aprofundamento nas questões relativas à divisão social do trabalho e ao reconhecimento das contribuições à vida coletiva. Daí que, para Zurn, a tentativa de Honneth de incluir na teoria do reconhecimento uma visão renovada da crítica distributiva arrisca-se ou a falsificar a realidade social ou a abdicar de seu ancoramento prático. No entanto, é preciso lembrar que no modelo concebido por Honneth as desigualdades materiais são parte de uma dinâmica mais ampla de desrespeito, estando contidas em processos que tomam a forma mais ampla de agressões morais. As tentativas de Honneth de atualização de um diagnóstico de tempo (Honneth 2007b e 2008) em direção a sentimentos de indeterminação da personalidade e abandono da intersubjetividade em função de uma prática reificada são passos importantes na construção de um paradigma amplo e abstrato o bastante para conter de forma unificada a idéia de justiça, mas são também elementos que permitem a conclusão de que ele parece caminhar em direção a uma grande preocupação com o momento normativo de seu modelo em detrimento de sua gramática social, que é justamente onde o modelo de Fraser parece ser mais positivo. Feita a ressalva de que Fraser não dispensa qualquer tratamento às dimensões psiquícas das lutas sociais, o fato de que sua apreensão dos conflitos empíricos - ou seja, do momento de imanência - é mais atenta do que a de Honneth, uma alternativa promissora para a proposta de reconstrução da Teoria Crítica, parece ser a de que seu modelo seja um momento contido no modelo de Honneth. Portanto, lembrando a lição de Horkheimer de que a Teoria Crítica é aquela em que o momento de imanência e o de transcedência são partes de uma mesma totalidade, a imersão do modelo de Fraser em uma teoria do reconhecimento como a de Honneth parece representar uma trilha promissora. 


\section{Bibliografia $^{14}$}

BLUM, Lawrence "Recognition, value and equality: a critique of Charles Taylor's and Nancy Fraser's accounts of multiculturalism" in Willett, Cynthia (ed.) Theorizing multiculturalism, Blackwell, Oxford, 1998.

DERANTY, Jean-Philippe "Injustice, violence and moral struggle. The critical potencial of Axel Honneth's theory of recognition" in Contemporary Perspectives in Social and Critical Philosophy, John Rundell, Danielle Petherbridge et al (eds.), Leiden, Brill, 2005.

FRASER, Nancy \& HONNETH, Axel. Redistribution or recognition. A political-philosophical exchange, Verso, London - New York, 2003

FRASER, Nancy "A rejoinder to Iris Young" in Willett, Cynthia (ed.) Theorizing multiculturalism, Blackwell, Oxford, 1998

. "Da redistribuição ao reconhecimento? Dilemas da justiça na era pós-socialista" in Souza, Jessé (org.) Democracia hoje. Novos desafios para a teoria democrática contemporânea, Editora Unb, Brasília, 2001, p. 245-282

"Rethinking Recognition", New Left Review 3, May-June, 2000, p. 107-120.

"Social justice in the age of identity politics: redistribution, recognition and participation", 2003a in Fraser, Nancy and Honneth, Axel. Redistribution or recognition. A politicalphilosophical exchange, Verso, London - New York, 2003

. "Distorted beyond all recognition: a rejoinder to Axel Honneth" 2003b in Fraser, Nancy and Honneth, Axel. Redistribution or recognition. A political-philosophical exchange, Verso, London - New York, 2003.

. "Reconhecimento sem ética" Lua Nova, n 70, 2007, São Paulo, p. 101-138.

\footnotetext{
${ }^{14}$ Alguns dos textos utilizados para esta redação foram publicados originalmente ou posteriormente em outros lugares, mas a fim de evitar confusões e delongas aqui estão citadas as edições utilizadas.
} 
Scales of Justice: Reimagining Political Space in a Globalizing World, Polity Press, Cambridge, 2008.

FREUNDLIEB, Dieter. "Rethinking Critical Theory" in Constellations, vol. 7, n¹, 2000, p. 80-99.

HABERMAS, Jürgen, "Técnica e Ciência enquanto ideologia", 1968 in Benjamin, W., Horkheimer, M., Adorno, T. W., Habermas, J. Obras escolhidas, Abril cultural, São Paulo, 1980 . The Theory of Communicative Action Volume 2 Lifeworld and system: A critique of funcionalist reason Beacon Press, Boston, 1987.

HEIDEGREN, Carl-Göran. "Anthropology, social theory and recognition: Axel Honneth's theory os recognition" in Inquiry. An interdisciplinary journal of phylosopy, vol. 45. $\mathrm{n}^{\circ} 4$, December 2002 "Symposium on Axel Honneth and Recognition".

HOBSON, Barbara "Introduction" in Hobson, Barbara (ed.) Recognition struggles and social movements, Cambridge University Press, Cambridge, 2003.

HONNETH, Axel. Luta por reconhecimento. A gramática moral dos conflitos sociais, Editora 34, São Paulo, 2003a.

. "Redistribution as recognition: a response to Nancy Fraser", 2003b in Fraser, Nancy and Honneth, Axel. Redistribution or recognition. A political-philosophical exchange, Verso, London - New York, 2003.

"The point of recognition: a rejoinder to the rejoinder", 2003c in Fraser, Nancy and Honneth, Axel. Redistribution or recognition. A political-philosophical exchange, Verso, London - New York, 2003.

. Disprespect. The normative basis of Critical Social Theory, Polity Press, Cambridge, 2007a

Sofrimento de indeterminação. Uma tentativa de reatualização da Filosofia do Direito de Hegel, Esfera Pública, São Paulo, 2007b.

Reification. A new look at an old idea. The berkeley Tanner lectures (edited by Martin Jay), Oxford University Press, New York, 2008. 
HORKEIMER, Max. "Teoria tradicional e Teoria Crítica" in Benjamin, W., Horkheimer, M., Adorno, T. W., Habermas, J. Obras escolhidas, Abril cultural, São Paulo, 1980a.

. "Filosofia e Teoria Crítica" in Benjamin, W., Horkheimer, M., Adorno, T. W., Habermas, J. Obras escolhidas, Abril cultural, São Paulo, 1980b.

ISIN, Engin F. \& WOOD, Patricia K. Citizenship and identity, SAGE, London/Thousand Oaks/New Dehli, 1999.

KAUPPINEN, Antti "Reason, recognition and internal critique" in Inquiry. An interdisciplinary journal of phylosopy, vol. 45, $\mathrm{n}^{\circ} 4$, December 2002 "Symposium on Axel Honneth and Recognition", p. 479-498.

MACLURE, Jocelyn "The politics of recognition at an impasse? Identity politics and democratic citizenship" in Canadian journal of political sciencel Revue canadienne de science politique, Vol. 32, $\mathrm{N}^{\circ}$ 1, Mar 2003, p. 3-21.

MATTOS, Patrícia. A sociologia política do reconhecimento. As contribuições de Charles Taylor, Axel Honneth e Nancy Fraser, Annablume, São Paulo, 2006.

MENDONÇA, Ricardo Fabrino. "Reconhecimento em debate: os modelos de Honneth e Fraser em sua relação com o legado habermasiano" in Revista de Sociologia e Política, n²9, Curitiba, nov. 2007.

NEVES, Paulo Sérgio. "Luta anti-racista: entre reconhecimento e redistribuição" in Revista brasileira de ciências sociais, vol. 20, $\mathrm{n}^{\circ}$ 59, outubro de 2005, p. 81-96.

PHILLIPS, Anne "Recognition and the struggle for political voice" in Hobson, Barbara (ed.) Recognition struggles and social movements, Cambridge University Press, Cambridge, 2003.

PINTO, Celi Regina Jardim. "Nota sobre a controvérsia HonnethFraser informada pelo cenário brasileiro" in Luz nova. Revista de cultura e política, $\mathrm{n}^{\circ}$ 74, 2008, p. 35-58.

RANKE, Wolfgan "Integrität und Anerkennung bei Axel Honneth" in Monatshefte, Vol. 97, $\mathrm{n}^{\circ}$, Summer 2005, p. 168-183. 
SANTOS, Boaventura de Sousa. "Nuestra America: reiventing a subaltern paradigm of recognition and redistribution" in Theory, culture \& society, vol. 18, no 2/3, 2001, p. 185-218, "Special Issue on: recognition and difference".

SEIDMAN, Steven and Alexander, Jeffrey C. "Introduction" in Seidman, Steven and Alexander, Jeffrey C. (eds.) The new social theory reader, Routledge, London/New York, 2001.

SILVA, Josué Pereira da. "A quem fala a Teoria Crítica? Reflexões sobre o destinatário de um discurso" in Waizbort, Leopoldo (Org.) A ousadia crítica. Ensaios para Gabriel Cohn, Editora UEL, Londrina, 1998.

. "Cidadania e reconhecimento" in Avritzer, Leonardo \& Domingues, José Maurício (orgs.) Teoria social e modernidade no Brasil, Editora UFMG, Belo Horizonte, 2000.

. "Teoria Crítica na modernidade tardia: sobre a relação entre redistribuição e reconhecimento", in. ANPOCS, Caxambu, 2005, 22p.

.Trabalho, cidadania e reconhecimento, Annablume, São Paulo, 2008.

" "Reconhecimento, redistribuição e as ambivalências do discurso sobre o Bolsa Família" in Ciências Sociais Unisinos, vol. 45, dez. 2009 (prelo).

SOUZA, Luiz Gustavo da Cunha de. "Reconhecimento como Teoria Crítica? A formulação de Axel Honneth", Dissertação de mestrado, Unicamp, 2009.

SWANSON, Jucinda "Recognition and redistribution. Rethinking culture and the economic" in Theory, Culture and Society vol. $22, \mathrm{n}^{\circ} 4,2005$, p. 87-118.

WILLETT, Cynthia "Introduction" in Willett, Cynthia Theorizing multiculturalism, Blackwell, Oxford, 1998.

YOUNG, Iris M. “Unruly categories: a critique of Nancy Frasere's dual systems theory" in Willett, Cynthia (ed.) Theorizing multiculturalism, Blackwell, Oxford, 1998.

ZURN, Christopher F. "Indentity or Status? Struggles over 'recognition' in Fraser, Honneth and Taylor" in Constellations, vol. 10, $\mathrm{n}^{\circ}$ 4, 2003, p. 519-537. 
"Recognition, redistribution and democracy: dilemmas of Honneth's critical social theory" in European journal of philosophy, Volume 13, Issue 1, April 2005, p. 89-126. 